\title{
DESENVOLVIMENTO DE UMA NOVA ÉTICA MUNDIAL: caminhos para uma agricultura incluída e inclusiva
}

Eugênio Dantas Gomes Lima Doutorando em Sustentabilidade Social e Desenvolvimento - DSSD. Professor Substituto da Faculdade de Economia, Administração e Contabilidade FEAC/UFAL. Universidade Aberta - Uab-Portugal/ CFE: Centre for Functional Ecology Science for People \& the Planet, Department of Life Sciences; University of Coimbra; E-mail:

eugenio.gdebrasil@gmail.com

\begin{abstract}
Resumo - A agricultura familiar e os territórios rurais possuem valores fundamentais para a sociedade. Assim, este trabalho faz parte de um processo investigatório que buscará compreender, por meio dos atores sociais, a sua percepção sobre os fenômenos que implicam seus territórios e a relação atual com as políticas públicas. Para isso, é necessário apresentar uma ampla discussão que possa problematizar a luz do Desenvolvimento Sustentável (DS), no contexto da "Modernidade Líquida" (BAUMAN). O debate aponta para a agricultura familiar ecológica como imprescindível fonte estratégica de desenvolvimento, tanto no espectro local como no global. Todavia, na realidade local, ainda prevalece formas de pobreza. Apresentamos, como saída, um modelo integrado e sistêmico do DS, composto por cinco dimensões: econômica, social, ambiental, política e cultural (NASCIMENTO). Desta forma, tendo como base a ação contemporânea nos territórios sertanejos que margeiam o canal do sertão alagoano, consideramos inicialmente que há emergência numa nova ética fundada nos valores dos territórios rurais sertanejos que são viáveis através da aplicação do DS na forma supracitada.
\end{abstract}

Palavras-chave: Territórios Rurais; Agricultura Familiar; Desenvolvimento Sistêmico; Ética Ambiental.

\section{DEVELOPMENT OF A NEW WORLD ETHICS: Pathways to Inclusive and Inclusive Agriculture}

\begin{abstract}
Family farming and rural areas have core values to society. This work is part of an investigative process that will seek to understand, through social actors, their perception of the phenomena involving their territories and the current relationship with public policies. For this it is necessary to present a broad discussion that can problematize the light of the Sustainable Development (DS), in the context of "Modernity Liquid" (Bauman). The debate points to the ecological family farming as an essential strategic source of development, both in the local and the global spectrum. However, the local reality, still prevalent, forms of poverty. Here, as output, an integrated and systemic model of DS, consisting of five dimensions - economic, social, environmental, political and cultural (NASCIMENTO). Thus, based on the contemporary action in sertanejos territories bordering the Alagoas hinterland channel, we consider initially that there is emergency a new ethics based on the values of sertanejos rural areas that are feasible by applying the DS in the above manner.
\end{abstract}

Key words: Rural Area; Family Agricultur; Systemic Development; Environmental Ethics.

\section{INTRODUÇÃO}

$$
\text { “... o indivíduo é o pior inimigo do cidadão...”. }
$$

Bauman

A compreensão da sustentabilidade tem se mostrado cada vez mais ampla e complexa, pois não é mais, somente, uma questão ambiental e econômica, mas, sobretudo e inclusive, é uma questão social, como também política e cultural (NASCIMENTO; 2012). As dimensões da sustentabilidade evidenciam seu espectro de ação que, estando mais vasto, pode significar que paulatinamente vai ficando claro que cada dimensão não pode ser avaliada de maneira isolada. $\mathrm{O}$ debate realizado por meio dos estudos produzidos aponta para a interdependência 
das dimensões. Mas a produção de mudanças concretas só poderá ocorrer com a integração entre as 05 (cinco) dimensões do Desenvolvimento Sustentável (DS) (ver figura, p. 10) ${ }^{1}$. E essa possível construção de canais de integração entre as dimensões, a nosso ver, é que se aproxima do sentido ecocêntrico apontando para o "modelo ideal" da escada de Susan Baker. Não se pode mudar a relação das indústrias e do capital com o meio ambiente sem trabalhar, bem antes, aspectos culturais e políticos dos seres humanos, comunidades e cidades.

A perspectiva de "transformação" vista no "mapeamento das diferentes abordagens sobre o desenvolvimento sustentável" de Bill Hopwood et al., representa um significativo avanço na compreensão do problema ambiental e as diversas abordagens possíveis de perceber o DS ao longo desse percurso histórico que vai formando o pensamento humano em torno desta questão. E uma conclusão é que não há a possibilidade de consensos. O "modelo Ideal” de Baker (2006) nos remete ao mapa de Hopwood et al. (2005), o que aponta para várias possibilidades. Contudo, uma mudança concreta requer atitudes e comportamentos diferentes que só podem ser encontrados nas características descritas nos extremos de cada "modelo" e, para isso, é necessário pensar uma sociedade menos desigual. Colabora nesse sentido Leonardo Boff quando reclama uma nova ética da Sustentabilidade e do Desenvolvimento, pois: "A crise é sistêmica e paradigmática. Reclama outro projeto civilizatório, alternativo, se quisermos salvar Gaia e garantir um futuro para a humanidade" (BOFF; 2006). De maneira a evitar a retórica, Boff trabalha, entre outros, com os dados fornecidos pelo Intergovernmental Panel on Climate Change (IPCC) (2014) ${ }^{2}$, que são contundentes e o apoia, para a realização de suas interpretações e conclusões que miram para um horizonte que requer uma urgência nas mudanças e, ainda, que essas sejam mais transformadoras do que ajustadoras e/ou mitigadoras. É necessária uma "nova ética por meio de uma nova ótica", enfatiza Boff (2006).

Podemos inferir que tais posicionamentos só podem vir a prosperar se pudermos "romper" com o modelo social e econômico hegemônico. Sendo isso uma utopia, no mínimo necessitamos de uma série de etapas e processos que possibilitem a abertura de novos caminhos de pensamento, mas que não serão garantia de sua execução. De qualquer maneira, quais são os caminhos? A terra suportará a espera desses processos? É evidente a percepção da necessidade de rever conceitos na

\footnotetext{
${ }^{1}$ A figura 1 (Diagrama do Processo Integrador e Sistêmico do DS), na página 10, mostra uma proposta de integração das 5 dimensões que foram apresentadas por Elimar Nascimento (2012). A nossa proposta é um modelo integrado. Somente assim poderemos obter resultados mais efetivos ao Desenvolvimento Sustentável (DS), dos territórios.

${ }^{2}$ Observações centrais do IPCC sobre: 1. Sistema: Warming of the climate system is unequivocal, and since the 1950s, many of the observed changes are unprecedented over decades to millennia. The atmosphere and ocean have warmed, the amounts of snow and ice have diminished, and sea level has risen. 2. Causa: Anthropogenic greenhouse gas emissions have increased since the pre-industrial era, driven largely by economic and population growth, and are now higher than ever. This has led to atmospheric concentrations of carbon dioxide, methane and nitrous oxide that are unprecedented in at least the last 800,000 years. Their effects, together with those of other anthropogenic drivers, have been detected throughout the climate system and are extremely likely to have been the dominant cause of the observed warming since the mid-20th century. 3 . Impactos: In recent decades, changes in climate have caused impacts on natural and human systems on all continents and across the oceans. Impacts are due to observed climate change, irrespective of its cause, indicating the sensitivity of natural and human systems to changing climate. 4. Eventos Extremos: Changes in many extreme weather and climate events have been observed since about 1950. Some of these changes have been linked to human influences, including a decrease in cold temperature extremes, an increase in warm temperature extremes, an increase in extreme high sea levels and an increase in the number of heavy precipitation events in a number of regions (IPCC; 2014).
} 
forma como se coloca a terra, numa perspectiva feminina apontando que as consequências, da atual ação humana, são devastadoras sobre a "Mãe Terra" e seus habitantes; ação historicamente capitaneada pelo gênero masculino conforme reclama Vandana Shiva que é também seguida por Leonardo Boff. Desta forma, uma das saídas para o processo de transformação, podemos inferir, é o constante empoderamento das minorias sociais.

Neste contexto, a noção de "Modernidade Líquida" descrita pelo sociólogo Zygmunt Bauman aborda tais problemáticas de uma maneira também bastante vasta apontando que a ação humana mercantiliza todas as atividades ligadas à manutenção da vida. Decorre disso uma forte individualização das atividades humanas que, assim, impedem o projeto de transformação e empoderamento. O comando de tudo é feito principalmente pelas corporações que mercantilizam inclusive a cultura (BAUMAN; 2001). Colabora, também, neste sentido Soromenho-Marques, quando argumenta que os elementos opositores a este modelo (mercantilizado) gera tensão principalmente pela crença dos conservadores que organizam a mentira e disseminam o medo desproporcional (MARQUES; 2012).

O debate ambiental e de alterações climáticas conforme afirma Soromenho-Marques não é um "jogo de soma zero", em que há "perdedores e ganhadores", pois, em verdade, o debate, “(...) é um jogo em que, ou todos ganhamos alguma coisa ou todos perdemos tudo (...)" (MARQUES; 2012). Para Shiva e Boff a relação homem-terra é interdependente, ou seja, não cabe a "soma zero". Isto está fortemente presente na fala de Shiva, quando ela reclama por uma intervenção na estrutura de poder mundial de tal forma que "novos valores culturais locais" possam emergir. Mas, o que e como? Shiva está se referindo também, neste contexto, à crise mundial, vivida atualmente, em que pode prevalecer a "soma zero". Isso é um risco ao "colapso mundial", pois em nome do bem-estar de uma minoria mundial está presente a guerra, a fome, a pobreza e a miséria de muitos (BEST, 2013; BOFF, 2006; SOROMENHO-MARQUES, 2012 e SHIVA, 2010).

Ainda é preciso dizer que estes especialistas informam que vivemos um momento violento sem precedentes, pois os conflitos, gerados pelas desigualdades social e econômica, são formas de violência, quem sabe as mais intensas. A violência começa na mente humana. A violência é contra a terra e contra os seres humanos por meio também do conflito armado. Mas a maior arma é a mente humana (SHIVA; 2010). Desta forma, Steve Best ${ }^{3}$ denuncia a violência do homem contra os animais e Vandana Shiva ${ }^{4}$

\footnotetext{
${ }^{3}$ Steven Best is an American animal rights advocate, author, and associate professor of philosophy at the University of Texas at El Paso.

${ }^{4}$ Dr. Vandana Shiva is trained as a Physicist and did her Ph.D. on the subject "Hidden Variables and Non-locality in Quantum Theory" at the University of Western Ontario in Canada. She later shifted to inter-disciplinary research in science, technology and environmental policy, which she carried out at the Indian Institute of Science and the Indian Institute of Management in Bangalore, India. In 1982, she left to set up her Research Foundation for Science, Technology and Natural Resource Policy in her home town of Dehra Dun in the foothills of the Himalaya. Her greatest learnings, however, have come from Mother Nature. Degrees: - PhD, Hidden Variables and Locality in Quantum Theory, 1978, University of Western Ontario, Canada: As part of the University's five year 'Colloquium on Quantum Theory' program. - M.A. in The Philosophy of Science, "Changes in the concept of periodicity of light”, 1977, University of Guelph, Ontario, Canada - Integrated M.Sc. Honours in Particle Physics, 1973 University of Punjab, Chandigarh, India. - Dr. Shiva has been a visiting professor and lectured at the 
estabelece uma profunda relação de violência e dominação humana sobre o próprio homem e sobre a agricultura. A diferenciação dos argumentos de Shiva e Best se dá, respectivamente, pelo seu ativismo ecofeminista que marca sua ação na busca de proteção às sementes e por uma agricultura livre de agrotóxicos e que possa disseminar novas formas de associação humana; seguido pelo ativismo em defesa dos animais que aponta para mudanças na forma como nos comportamos na alimentação e, ambos, validados por estudos científicos. Estas características definem muito desses argumentos.

O trabalho está dividido em duas grandes partes. A primeira trata da agricultura familiar com foco no modelo ecológico. Apontamos fortemente a contribuição da física Vandana Shiva e do cientista social Sérgio Schneider que debatem, respectivamente, o meio ambiente (ecologia) e o impacto nas políticas públicas voltadas a esses atores sociais. A segunda parte tem a defesa, junto com Bauamn e Nascimento, de uma "nova ética" que deve ser baseada nos valores já existentes nos modelos rurais e familiares de produção na agricultura com a incorporação das modernas técnicas de cunho agroecológico. Este conjunto de ações e referências pode levar a humanidade a um nível de desenvolvimento por meio de uma $4^{\mathrm{a}}$ revolução, a da consciência.

\section{A AGRICULTURA FAMILIAR COMO ALTERNATIVA? PROPONDO UM ESTUDO DE CASO NOS TERRITÓRIOS RURAIS APÓS CANAL DO SERTÃO EM ALAGOAS-BRASIL}

\section{AGRICULTURA FAMILIAR ECOLÓGICA}

A introdução deste trabalho busca apontar, por meio de renomados especialistas supracitados, para a necessidade urgente de uma profunda reflexão sobre nosso modo de vida atual. Pode ser verdade que alternativas já existem e possivelmente o que buscamos seja o reconhecimento de modos de vida que contém os elementos necessários. É possível perceber isso nos vários autores consultados e o que nos falta, em relação a essas alternativas, é reconhecê-las e dispô-las de novos conhecimentos que podem melhorar a qualidade de vida preservando a natureza cultural e ambiental comunitária. É possível afirmar que a agricultura familiar ecológica é um caminho? Buscamos em Shiva (2010) uma possibilidade de uma profunda reflexão neste sentido. Shiva nos indica que as estratégias das grandes corporações, ligadas ao agronegócio, têm contribuído enormemente para o fortalecimento de padrões de vida e de consumo que se choca com os objetivos de desenvolvimento sustentável e acirram a desigualdade e exclusão social.

A transformação desse modelo de controle e poder capitaneado pelas grandes corporações do agronegócio já poderia indicar uma alternativa. Shiva argumenta que a

University of Oslo, the University of Norway, Schumacher College (UK), Mt. Holyoke College (US), York University (Canada), University of Lulea (Sweden), University of Victoria (Canada) and the Universite libre de Bruxelles (Belgium). In 2011, Dr. Shiva was the Wayne Morse Chair at the University of Oregon in Eugene. Dr. Shiva has received honorary Doctorates from the University of Paris, the University of Western Ontario, the University of Oslo, Connecticut College, University of Toronto, University of Victoria, and the University of Guelph. Fonte: http://vandanashiva.com/ 
proteção das sementes é uma ação estratégica, pois são inúmeros os benefícios sobre as pessoas e a qualidade na produção de alimentos. Somente assim poderemos contrapor às ameaças existentes a produção "limpa" de alimentos que é comumente chantageada pela possibilidade de modificações genéticas, que são apontadas como uma saída necessária à superpopulação, mas que na verdade ameaçam a reprodução e posse das sementes (SHIVA).

A agricultura ecológica não aceita as modificações genéticas, tanto porque é livre de agrotóxicos, e também pelo fato de representarem a vida e a saúde, como também pela liberdade de inúmeras comunidades espalhadas pelo mundo (SHIVA). Infere-se que a utilização da terra com plantações de culturas mistas, que favoreçam a biodiversidade, impedindo a monocultura, é outra importante estratégia. Shiva, ainda, afirma que a agricultura ecológica oferece mais vantagens e é um grande contraponto ao modelo industrial de agricultura, hegemônico desde a revolução industrial capitaneada pelo gênero masculino (SHIVA).

Fica subjacente na argumentação de Vandana Shiva que é preciso repensar a forma de vida em sociedade, para que um novo modelo alternativo possa ganhar força e contrapor o poder das corporações. As indústrias não estão produzindo melhores alimentos e sim uma maior quantidade agravada pelo fato de não atender a todos, o que acirra e mantém os índices de desigualdade. Somente a agricultura ecológica pode transformar, paulatinamente, o planeta, pois o foco é tanto na terra como no ser humano (SHIVA).

E neste sentido o "mundo rural" pode se tornar uma alternativa podendo alcançar altos níveis de qualidade na produção, sendo necessária, para isso, a criação e execução de obras de infraestrutura básica e acompanhamento técnico adequado à realização das atividades de campo.

\section{ALAGOAS, TERRITÓRIOS RURAIS E OS AGRICULTORES FAMILIARES}

Neste tópico apresentamos na forma de um Estudo de Caso ${ }^{5}$ aspectos sociais, econômicos e políticos, oriundos da observação da vida em alguns dos territórios rurais alagoanos na perspectiva de debater futuramente o impacto, com base nas cinco dimensões do desenvolvimento sustentável, propiciado por meio das "novas" políticas públicas adotadas para estes territórios situados no Estado de Alagoas. Este Estado da federação é considerado um dos mais pobres do país e está situado no nordeste do Brasil, afetado pelas secas que devastam o ambiente natural. Mas, a nossa inquietação será sempre a de perceber como essa política pública pode interferir na dimensão imaterial da pobreza, ou seja, na dimensão política e cultural do Desenvolvimento Sustentável (DS).

\footnotetext{
${ }^{5}$ Este trabalho é uma discussão preliminar que em breve fará parte de uma pesquisa de campo que buscará compreender a relação de comunidades rurais do sertão de Alagoas, no Brasil, com a chegada de obras estruturantes e sua "nova" relação com as políticas públicas voltadas a agricultura familiar e seus agricultores.
} 
Para se ter uma noção do problema, os números oficiais do governo federal brasileiro apontam para 422 mil famílias recebedoras do PBF no Estado de Alagoas, que recebem, mensalmente, o valor médio de $\mathrm{R} \$ 172,00$ por família, que equivale a aproximadamente $€ \$$ 42,26. Essas famílias totalizam quase 1 milhão e 700 mil pessoas diretamente beneficiadas que correspondem a 50,3\% da população alagoana. Isso significa um repasse anual de 872 milhões de reais depositados diretamente às famílias que viabilizam uma "nova" Economia Popular e Solidária, conforme nos explica o economista Cícero Péricles de Carvalho. Comparando ao Brasil, a quantidade chega a 13 milhões e 800 mil famílias que totalizam quase 55 milhões de pessoas diretamente beneficiadas correspondendo a 27,05\% da população brasileira. O repasse anual é da ordem de 27 bilhões de reais que equivale a aproximadamente $€ \$ 6,6$ bilhões de euros. A prioridade para o recebimento é para mulheres e esses desembolsos mobilizam a economia dos municípios e representam a possibilidade de melhoria nas condições de vida dessas populações.

A primeira inquietação de muitos especialistas sempre foi o de saber se o foco na transferência de renda voltada para o consumo imediato pode interferir negativamente na construção política do ser (superestrutura), pois reforçaria uma relação de dependência com o Estado. Uma das preocupações é compreender que, se política pública se resumir somente à transferência de renda ela pode se tornar insustentável. Além disso, a ação nos territórios pode vir a desvirtuar e ser mal conduzida pelo governo local reforçando a prática de mazelas históricas oriundas do modelo de colonização do Brasil. Todavia, conforme aponta Schneider (2015) et al., "O Programa Bolsa Família, é considerado um dos principais fatores de redução da pobreza no meio rural do Brasil na última década" (SCHNEIDER, p. 445). Dessa forma, podemos elencar 4 objetivos centrais para uma futura pesquisa empírica oriunda deste projeto de Estudo de Caso: 1) Compreender a dinâmica das 5 dimensões do DS nos territórios rurais em questão; 2) Elencar todas as Políticas Públicas que podem viabilizar a integração do DS e que atuam junto a essa população; 3) Levantar as ações estruturantes e de inovação que estão sendo ofertadas no meio rural sertanejo alagoano; e, por fim, 4) Compreender como o indivíduo tem participado na construção e viabilização de projetos e ações coletivas que busquem juntamente com o Estado a mudança de sua realidade social em rede.

Todavia, o que tem sido apontado é que, contraditoriamente, as evidências atuais de uma má conduta política de alguns governos locais, o PBF (Programa Bolsa Família) tem demonstrado capacidade de elevação do poder de ação do indivíduo, por meio de ações estruturantes e/ou "complementares" que têm afetado positivamente as famílias, inclusive com a própria transferência de renda, que é repassada diretamente à família, sem intermediários (CARVALHO, 2005). Com isso, os descendentes das famílias recebedoras são diretamente e positivamente afetados. Infere-se que a renda permite, no futuro, independência 
política em relação ao mando local. Esse fato, associado a outros programas governamentais (Educação), modificam a perspectiva cultural, principalmente dos mais jovens inclusive das mulheres. Assim, a tutela estatal também pode estar sendo vencida por meio do empoderamento dos jovens e mulheres, como foco no meio rural. A sustentabilidade dessa política pública está ligada às suas ações que vão além da transferência de recursos financeiros. Mas, como as novas gerações estariam construindo esse processo? Como as oportunidades estruturais estão sendo ofertadas aos descendentes e como afetam os indivíduos e o lugar? Questões preliminares para um debate futuro.

Destacamos neste sentido a contribuição de Schneider (2015) et al.:

\begin{abstract}
Em seu livro seminal, Desenvolvimento como Liberdade, Sen (2000) analisou a relação entre a renda e as realizações individuais e questionou o entendimento da renda como um fim em si mesmo, destacando a necessidade de considerá-la como um meio que permite aos indivíduos realizarem aquilo que gostariam. Segundo Sen (2000), a renda não e o único fator a influir na qualidade de vida, e nem mesmo essa influência pode ser padronizada, uma vez que o impacto da renda na vida e variável (SCHNEIDER; 2015, p. 444).
\end{abstract}

E é neste sentido que temos buscado identificar quais fatores podem apontar para possíveis mudanças que vão além da transferência de renda que, mesmo sendo imprescindível, deve ser acompanhada de soluções que viabilizem mudanças por meio da adoção de uma infraestrutura que possa criar condições para uma nova superestrutura. Mas, saber qual o nível de integração e participação política nas decisões que estão por vir é desafiador, pois convém lembrar que:

\begin{abstract}
As poucas informações disponíveis sobre os beneficiários rurais do Programa Bolsa Família não permitem conhecer sua realidade de forma mais aprofundada, impedindo que as relações do programa com outras iniciativas para a inclusão sócio produtiva das famílias sejam conhecidas. Pouco se sabe sobre a relação entre o PBF e o Pronaf, um dos principais programas de apoio à agricultura familiar, e o Programa de Aquisição de Alimentos (PAA), por exemplo. Além disso, o Pronatec, que oferece formação técnica para as famílias de baixa renda, ainda não teve seus resultados amplamente explorados, sobretudo no que concerne ao meio rural. Dessa forma, os estudos disponíveis ainda não foram suficientes para demonstrar as possíveis sinergias entre as políticas públicas hoje disponíveis para garantia de renda e inclusão social e produtiva das famílias pobres e extremamente pobres (SCHNEIDER; 2015, p. 458).
\end{abstract}

Além das inúmeras políticas públicas, enumeradas por Schneider em suas pesquisas, e que ainda carecem de amadurecimentos, visualizamos inicialmente, para este caso, que será objeto de estudos posteriores a apresentação das duas grandes obras que podem ter bastante impacto nestes territórios sertanejos. Devemos avaliar a política de infraestrutura, no caso dos territórios sertanejos que são: o canal do sertão alagoano ${ }^{6}$ e a ampliação do campus da

\footnotetext{
${ }^{6}$ A obra, quando concluída, terá 250 quilômetros de extensão, levando água para cerca de um milhão de pessoas em 42 municípios de Alagoas, melhorando a qualidade de vida na região e desenvolvendo a economia local. Só a primeira etapa da obra, já inaugurada e com 65 quilômetros de extensão, contribuiu para a geração de mais de 15 mil empregos e com a irrigação de seis mil hectares de terra. O investimento total na obra é de R \$1,5 bilhão. Além do consumo humano, a água do Canal do Sertão Alagoano servirá também para a atividade agrícola nos municípios de Delmiro Gouveia, Pariconha e Água Branca. Fonte: Governo Federal: http://www.pac.gov.br/
} 
Universidade Federal de Alagoas (UFAL). Estes equipamentos podem apontar respostas futuras na construção de uma nova superestrutura por meio das próximas gerações, pois:

\begin{abstract}
Uma vez que o desenvolvimento, na perspectiva Seniana, envolve ampliar as liberdades, não apenas a renda das famílias, as políticas de crédito e de formação profissional são uma potencial resposta para a sustentabilidade de renda das famílias em situação de vulnerabilidade. Notadamente, tais políticas precisam estar de acordo com as necessidades dos agricultores familiares, uma vez que existir crédito e formação profissional não significa que necessariamente as famílias pobres farão uso desses recursos (SCHNEIDER; 2015, p. 461).
\end{abstract}

Estas necessitam de oportunidades que em parte já estão presentes na rica cultura do local e que podem apenas precisar da introdução dos benefícios gerados pela ciência tornando mais fáceis e eficazes suas práticas agrícolas locais incrementadas por novas tecnologias e conhecimentos. Os equipamentos citados podem se tornar canais de ampliação das liberdades conforme explica o economista indiano Amartya Sen.

\title{
POR UMA “NOVA ÉTICA CIDADÃ": o peso da dimensão política e cultural
}

Abrimos esse tópico com a contribuição de Soromenho-Marques abordando, agora, a sua quarta questão: "Seremos capazes de reinventar a cidadania para as tarefas do desenvolvimento sustentável?". Pode ser essa a questão mais importante, pois remete à formação de nova mentalidade humana, que levem em consideração novos valores em relação ao outro e ao planeta. Decorre disso uma nova forma de associação humana; novas formas de produção e uma nova perspectiva de cultura de felicidade.

Cabe reconsiderar e reinterpretar esse processo. São olhares complementares que visam repensar a ideia de progresso e para isso teremos também a colaboração de uma "nova" ciência e tecnologia (MARQUES).

Existem inúmeras alternativas sendo atualmente testadas no mundo que têm impacto sobre a cultura. Energia renovável, produção de energia solar, transporte público elétrico, uso de bicicletas para pequenas e médias distâncias, redução na utilização do automóvel particular, estratégias educacionais, aplicação de taxas de acesso e uso (água, energia, estacionamento, etc.), valorização dos espaços públicos, etc. Esses são alguns exemplos que podem se firmar como uma das "Several key government policies can help cities move towards sustanaibility" (NEWMAN; 2009).

Para isso, são criados e gerenciados programas de mudança cultural que buscam a mutação por meio da construção de uma nova visão de mundo individual e social e, assim, a comunidade é envolvida como no caso do exemplo citado por Peter Newman (2009), sobre o trabalho do sociólogo Alemão Werner Brog responsável por um programa em que afirma o reconhecimento do princípio fundamental da mudança cultural: "it works best when the 
change is supported by a community it is part of the development of social of network that support the change in lifestyle".

Entendendo a Mudança Cultural como ponto crucial para criar uma governança sustentável, podemos perguntar: Quais são as estratégias para a efetividade e como realizá-las de maneira eticamente sustentáveis nos territórios?

O exemplo supracitado é uma referência de políticas públicas concretas e que podem ser reproduzidas no contexto de inúmeros governos de municípios em lugares diferentes do mundo. Entender eticamente o que essas experiências estão fazendo para promover a Mudança Cultural (questão chave para o Desenvolvimento Sustentável) pode vir a ser a grande questão ética de uma governança transformadora.

Desta forma, propomos um modelo integrado para o Desenvolvimento Sustentável que possibilite que as 5 dimensões possam trabalhar para a transformação. O processo de transformação somente pode obter êxito se culminar na produção de uma nova Ética Mundial.

Figura 1. Diagrama do Processo Integrador e Sistêmico do DS.

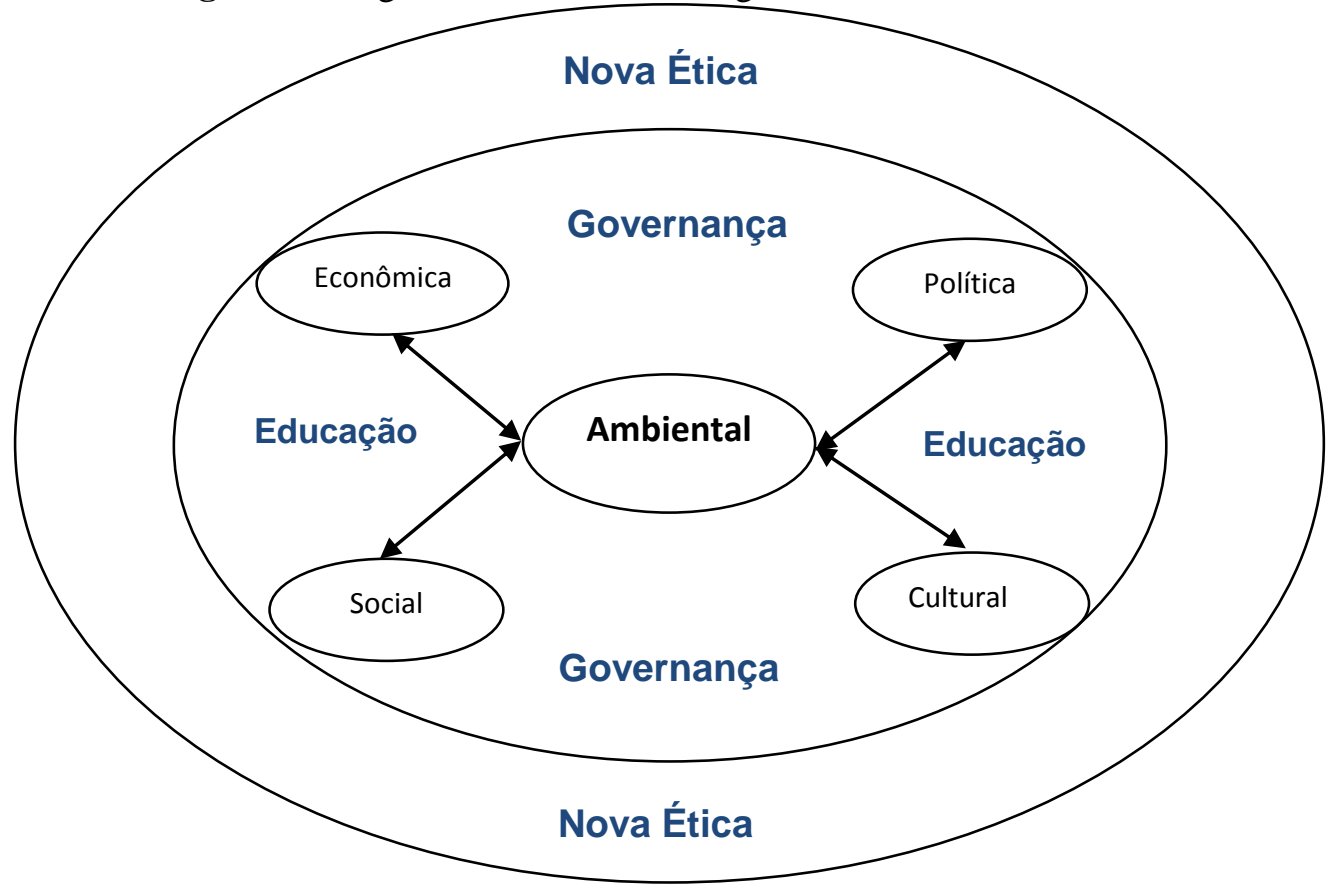

Fonte: Produção Própria, por meio da argumentação de Elimar Nascimento (2012).

A governança e a educação farão frente à estratégia social que poderá criar a aliança necessária para que o processo de integração entre as partes e as dimensões que formam o conceito de DS possa fluir e se integrar tendo a dimensão ambiental como força motriz das transformações.

A nosso ver, só é possível o alcance dessa meta, proposta pelo diagrama acima, se as características centrais da modernidade em estado "líquido" forem superadas, e isso só pode 
ocorrer com as mudanças no campo político. Para isso, estratégias de educação que ataquem a pobreza imaterial, são necessárias para uma mudança de cultura. Daí a importância da dimensão política que interfere no campo subjetivo do ser humano. Como fazer a mudança?

\begin{abstract}
A primeira resposta é a tecnológica, que deposita na capacidade inventiva do homem a superação anunciada dos limites dos recursos naturais. A segunda reside na mudança radical (mas progressiva) do padrão de produção e consumo vigente, expressa no movimento do decrescimento, entre outros (NASCIMENTO; 2012, p. 59).
\end{abstract}

Tal movimento, da segunda resposta, só pode ser levado a cabo através de processos educativos que construam uma nova visão de mundo, ou seja, que leve a um comportamento social pós-moderno. Somente assim pode-se vencer o individualismo característica política central da "Modernidade Líquida" (BAUMAN).

Neste sentido, afirma Bauman sobre a questão da individualização:

\begin{abstract}
Em suma: o outro lado da individualização parece ser a corrosão e a lenta desintegração da cidadania. (...) Se o indivíduo é o pior inimigo do cidadão, e se a individualização anuncia problemas para a cidadania e para a política fundada na cidadania, é porque os cuidados e preocupações dos indivíduos enquanto indivíduos enchem o espaço público até o topo, afirmando-se como seus únicos ocupantes legítimos e expulsando tudo mais do discurso público (...) (BAUMAN, 2001, p. 46).
\end{abstract}

O diagrama do processo integrador do DS é baseado em Nascimento (2012) que nos traz uma construção muito didática do conceito de DS. Acrescentamos aqui a sociologia de Bauman que colabora com Nascimento ao apontar para as raízes dessa complexidade que está diretamente ligada a formação industrial de nossa sociedade. Assim, não se pode apenas mudar em aspectos econômicos ou financeiros, aportando recursos monetários, etc., pois antes, é necessário construir novas oportunidades.

O que buscamos, inicialmente, é realizar uma reflexão de como trazer à tona o papel do "novo" cidadão politizado que possa ir ao encontro da perspectiva do DS. A nosso ver, a mudança se dará por um caminho que naturalmente leva o homem a um "novo" conceito de felicidade como aponta Zidansek (2007). Para o alcance disso é necessário à inversão dos valores. Quem sabe para valores mais "sólidos"? É possível inferir essa necessidade de Nascimento, quando conclui que:

(...) Ora, não será possível haver mudança no padrão de consumo e no estilo de vida se não ocorrer uma mudança de valores e comportamentos; uma sublimação do valor ter mais para o valor ter melhor; se a noção de felicidade não se deslocar do consumir para o usufruir; se não se verificar a transferência da instantaneidade da moda para a durabilidade do produto (NASCIMENTO, 2012, p. 57).

Já Bauman, neste sentido, afirma que:

A tarefa de construir uma ordem nova e melhor para substituir a velha ordem defeituosa não está hoje na agenda - pelo menos não na agenda daquele domínio em que se supõe que a ação política resida. O "derretimento dos sólidos", traço permanente da modernidade, adquiriu, portanto, um novo sentido, e, mais que tudo, 
foi redirecionado a um novo alvo, e um dos principais efeitos desse redirecionamento foi à dissolução das forças que poderiam ter mantido a questão da ordem e do sistema na agenda política. Os sólidos que estão para ser lançados no cadinho e os que estão derretendo neste momento, o momento da modernidade fluida, são os elos que entrelaçam as escolhas individuais em projetos e ações coletivas (...) (BAUMAN, 2000, p. 13). Grifo nosso.

Como faremos isso? Por meio da Educação como instrumento de formação política para a construção de uma nova cultura de relacionamento social, político, econômico e cultural, puxado pelas demandas ambientais que deve ir ao encontro dos Objetivos do Desenvolvimento Sustentável - 2030. Na agenda, a ação política ambiental podemos interpretar, é a trama que interliga os 17 objetivos e suas metas.

Quem sabe esse "novo" modelo cultural já exista, mas o modelo neoliberal hegemônico e globalizado não permite que tais formas diferenciadas de organização social tenham voz e ação. De maneira bastante resumida, o retorno do exercício da política, conforme aponta Bauman, se dará por meio da valorização do debate público de qualidade. Uma das mazelas centrais para a manutenção do status quo conservador é a falta da boa política que individualiza o homem criando relações sociais frágeis baseadas somente em interesses comerciais. Isso não nos leva a uma perspectiva de desenvolvimento, seja social, ou em qualquer uma das dimensões.

\section{CONSIDERAÇÕES “FINAIS”...}

Em virtude dos fatos apresentados, percebemos que há um sentimento social de que algo novo precisa ser trazido à tona para revitalizar a vida. Uma nova ética para a sustentabilidade pode ser um caminho para a transformação nas relações sociais, e destas com o ambiente, o que muito se aproxima da proposta de "uma terceira transição ou transformação" (HABERL, et al., 2011) ${ }^{7}$. O que seria uma terceira transição, uma vez que a segunda significou a transição do modelo agrário para a sociedade industrial? Em uma possível sociedade agrária ecológica, haveria o reencontro da felicidade podendo ser um modo de vida a representar o desenvolvimento sustentável?

Conforme argumentamos ao longo desse texto, defendemos a educação como o principal eixo de transformação. Para Zidansek (2007):

It is important that sustainability is integrated in education, and that international networking promotes examples of good practice, where people achieve both happiness and sustainability. A very good strategy closely linked with education is also to promote a transition from materialistic to postmaterialistic values. An empiric relation between

\footnotetext{
${ }^{7} \mathrm{We}$ are convinced, and have provided ample empirical evidence from a long-term perspective (see FischerKowalski and Haberl, 2007; Krausmann et al., 2008a; Sieferle et al., 2006), that fundamental and not only gradual changes in our interaction with natural systems are necessary for human survival. Social metabolism, that is, the amount of energy and matter used, has to decrease markedly, and land use has to be re-organized into a net energy producing system. While we have no clear vision of the make-up of the resulting society, we can infer from historical data how fundamentally different from the present pattern it would have to be as result of the third Great Transformation (HABERL, et al.; 2011).
} 
happiness and importance of love and money shows that people with postmaterialistic values are happier than people with materialistic values (ZIDANSEK, p. 896).

A educação deve conter os elementos centrais para facilitar a transição. Mas se as bases atuais do capitalismo é que ditam o próprio modelo de educação, será possível construir uma nova metodologia? É urgente definir uma ética para a sustentabilidade e para a educação.

Os valores devem convergir na construção de uma sociedade mais voltada a "cooperação compulsiva" como aponta Soromenho-Marques em que possamos "fortalecer a participação política local sem perder a visão global" (MARQUES). O caminho pode ser um forte modelo de educação ambiental, que consiste na valorização dos conhecimentos tradicionais; propulsão de saberes científicos sobre o planeta e as interações sócio-metabólicas em construção apontando novas possibilidades de associação humana que se beneficiem dos recursos tecnológicos e científicos que deverão ser aplicados ao contexto local, etc.

Compartilhamos as principais conclusões de Simon Dresner, por meio do trabalho de John Rawls "A theory of justice”, ou seja, a nova noção de sustentabilidade é mais compatível com um modelo socialista (DRESNER, 2002). Teremos, assim, um processo lento, incerto e que requer estratégias de educação, reflexão e mudança cultural que possibilitem a inclusão social que, primeiramente, deve ser incluída na agenda nacional e global.

A vida rural, seus territórios e a agricultura familiar, são caminhos de inclusão que precisam, antes, ser também incluídos ao processo de desenvolvimento (ABRAMOVAY, 2003; SCHNEIDER, 2004).

Em suma, é inegável que poderemos construir uma noção de felicidade diferente, embasada nestes novos valores. Em nossa opinião, isso deve contagiar a sociedade levando à transformação tendo como ator indispensável o novo cidadão.

\section{REFERÊNCIAS}

ABRAMOVAY, Ricardo. O futuro das regiões rurais. Porto Alegre: UFRGS, 2003.

Agricultura Familiar e Desenvolvimento Territorial. Reforma Agrária - Revista da Associação Brasileira de Reforma Agrária - vols. 28 ns 1,2 3 e 29, nº 1 - Jan/dez 1998 e jan/ago 1999.

AGENDA 2030 para o Desenvolvimento Sustentável. Transformando Nosso Mundo: Objetivos do Desenvolvimento Sustentável, 2015.

BAKER, Susan. Sustainable Development, Routledge; 2006.

BAUMAN, Zygmunt. Em Busca da Política. Rio de Janeiro: Jorge Zahar Ed; 2001.

Modernidade Líquida. Rio de Janeiro: Jorge Zahar Ed; 2000.

BEST, Steve: Ecological Crisis and Veganism, IARC 2013, Luxembourg. https://www.youtube.com/watch?v=mkvss2bY5HA

BOFF, Leonardo. Ética e sustentabilidade. Caderno de Debate da Agenda, 21. 2006

CARVAlHO, Cícero Péricles. Economia Popular: uma via de modernização para Alagoas. Maceió: EDUFAL, 2005. 
DRESNER, S. The principles of sustainability. Earthscan. 2002

HABERL, Helmut. A Socio-metabolic Transition towards Sustainability? Challenges for Another Great Transformation. Sustainable Development; 2011

HOPWOOD, Mellor e O'Brien. Sustainable Development: Mapping Different Perspectives, Sustainable Development; 2005.

IPCC, 2014: Climate Change: Synthesis Report. Contribution of Working Groups I, II and III to the Fifth Assessment Report of the Intergovernmental Panel on Climate Change [Core Writing Team, R.K. Pachauri and L.A. Meyer (eds.)]. IPCC, Geneva, Switzerland, 151 pp.

JACOBI, P. Educação ambiental, cidadania e sustentabilidade. Cadernos de Pesquisa, n. 118, 189-205; 2003.

MEER, Shamim. SEVER, Charlie. GENDER and CITIZENSHIP: Overview Report. Institute of Development Studies - IDS, 2004.

NASCIMENTO, Elimar Pinheiro do. Trajetória da sustentabilidade: do ambiental ao social, do social ao econômico. Estudos Avançados 26 (74), 2012.

Portal do Instituto Brasileiro de Geografia e Estatística - IBGE. Disponível em: <http://www.ibge.gov.br/home/ . Acesso em Março/2016.

Portal da Transparência. Disponível em: <http:// www.portaldatransparencia.gov.br>. Acesso em Março/2016.

Portal do Ministério do Desenvolvimento Social e Combate a Fome - MDS Disponível em: <http://www.mds.gov.br. Acesso em Março/2016.

SANTOS, Milton. O Espaço do Cidadão. São Paulo: Nobel; 1987. (Coleção espaços).

A natureza do espaço: espaço e tempo: razão e emoção. 3.ed. São Paulo: Hucitec, 1999.

SOROMENHO-MARQUES. Viriato. Alterações climáticas: a crise que não sabemos pensar 4 - As alterações climáticas e o enigma do nosso futuro comum. Viriato Soromenho Marques, 2012. https://vimeo.com/43423538

SCHNEIDER, Sergio e CASTILHO E SILVA, C. B. de. Pobreza rural e o Programa Bolsa Familia desafios para o desenvolvimento rural no Brasil. (443-463) In: Políticas públicas de desenvolvimento rural no Brasil / Organizadores Sergio Schneider e Catia Grisa [e]- Porto Alegre: Editora da UFRGS, 2015.

SCHNEIDER, Sergio e TARTARUGA, Iván G. Peyré. Território e Abordagem Territorial: das Referências Cognitivas aos Aportes Aplicados à Análise dos Processos Sociais Rurais. Campina Grande: Raízes, Vol.23, № 01 e 02, 2004.

SCHNEIDER, Sergio. A abordagem territorial do desenvolvimento rural e suas articulações externas. Sociologias, Porto Alegre, ano 6, n. 11, p. 88-12, 2004.

SCHEURER, J., e NEWMAN, P. Vauban: A European model bridging the green and brown agendas. Unpublished case study prepared for the Global Report on Human Settlements. 2009.

SEN, Amartya. Sobre Ética e Economia. São Paulo: Ed. Companhia das Letras, 1999.

Desenvolvimento como Liberdade. São Paulo: Ed. Companhia das Letras, 2000.

SHIVA, Vandana: Sydney Peace Prize Talk. 2010. https://vimeo.com/17376439

VEIGA, José Eli da. A face territorial do desenvolvimento. INTERAÇÕES - Revista Internacional de Desenvolvimento Local. Vol. 3, N. 5, Set. 2002.

ZIDANSEK. Aleksander. Sustainable development and hapiness in nations. Energy; 2007.

Zero poverty, zero emissions. Eradicating extreme poverty in the climate crisis. Overseas Development Institute - ODI. Report, 2015. 